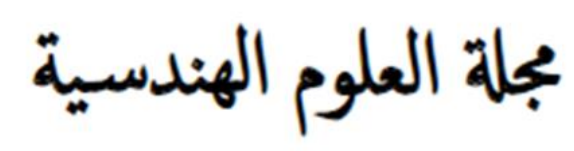

\title{
Modelling of Compressive Membrane Action for Fully-laterally Restrained Two-way R.C Slabs
}

\author{
Rammah Ahmed Mohammed Wagieallah ${ }^{1, *}$, Mohammed Tagelsir Mustafa Abdelsalam ${ }^{1}$ \\ 1 Civil Engineering Department, University Of Khartoum, Khartoum, Sudan \\ * Corresponding author: Rammah A. M. Wagieallah (e-mail: Rammahramm@gmail.com). \\ Article history: Received 13 March 2020, Received in revised form 4 November 2020, Accepted 11 November 2020
}

\begin{abstract}
Current design codes do not account for the effect of compressive membrane action (CMA) in reinforced concrete slabs, which can increase their capacities, and hence yields more economical design. This paper studies the influence of CMA for laterally restrained two-way slabs. The main aim is to develop a simple model to reasonably predict the enhancement in load-carrying capacity due to CMA for laterally restraint two-way RC slabs under uniformly distributed loading. In order to meet this aim, a numerical technique was used. The developed model had been validated against relevant experimental studies from literature. The parameters influencing the CMA were identified. These included the reinforcement ratio and span-thickness ratio. It was shown that the CMA decreases by increasing the percentage of reinforcement and span-to-thickness ratio. After that, a numerical model for evaluating the CMA for laterally restrained two-way slabs has been proposed. The model was examined against 43 slab specimens from literature. The correlation achieved was satisfactory, despite the wide range of variables involved in tests. The mean ratio of the experimental to the predicted ultimate load was 1.00, and the coefficient of variance (COV) equal to $25 \%$.
\end{abstract}

Keywords: Arch action, compressive membrane action, restrained slab, two-way slab.

\section{NOTATIONS:}

h Depth of slab "m"

d Effective depth of slab "mm"

$\mathrm{f}^{\prime} \mathrm{C} \quad$ Concrete cylinder compressive strength "MPa"

fy Reinforcement yield strength "MPa"

L Span of slab "m"

Lr Half span of elastically-restrained strip "m"

$\rho \quad$ Positive reinforcement ratio"\%"

$\mathrm{Mb} \quad$ Bending moment capacity "kN.m"

m Bending moment capacity "kN.m/m"

$\mathrm{Nj} \quad$ Failure load from Johansson's yield line method "kN/m"

$\mathrm{Np} \quad$ Failure load from proposed method "kN/m²"

$\mathrm{Nt} \quad$ Failure load from test " $\mathrm{kN} / \mathrm{m}^{2}$ "

YLM Yield line method

CMA Compressive membrane action

\section{INTRODUCTION}

The need to reduce the environmental impacts of the construction and manufacturing industries is an important issue. Hence, avoiding the over-sizing structural elements, such as slabs, is an important step. Many researchers [1]-[6] have shown experimentally that under the effects of compressive membrane action (CMA) reinforced concrete slabs have higher capacities than calculated by yield line method. The size of structural elements could be reduced if the beneficial effect of CMA could be accounted for in the design.

The compressive membrane action or arching action is developed due to the deflection of reinforced concrete slabs. Such deflections result in cracking of the section in the tensile zone which changes the neutral axis (NA) position from its initial elastic one. This, in turn, causes an axial 
extension of the member as the neutral axis moves towards the compressive fiber. If this extension is prevented by axial/lateral restraints, such as that provided by end span columns, walls, adjacent beams and adjoining slab panels, a compressive thrust is generated in the member as shown in Fig. 1. This phenomenon can considerably increase the capacity of RC slabs [1], [3]-[8].

\section{A. Aim}

The aim of this paper is to identify factors affecting the compressive membrane action in laterally restrained R.C two way slabs and develop a simple numerical model to evaluate it.

\section{B. Research Objectives}

A numerical analysis for tests from literature, which consist of 43 specimens of two-way reinforced concrete slabs, had been considered. The specimens were fully restrained about all edges. The variable parameters of the specimens were as follows:

- Span-to-height ratios were $15,20,30,40$, and 60.

- The concrete compressive strength was ranged from “22-45” $\mathrm{MPa}$.
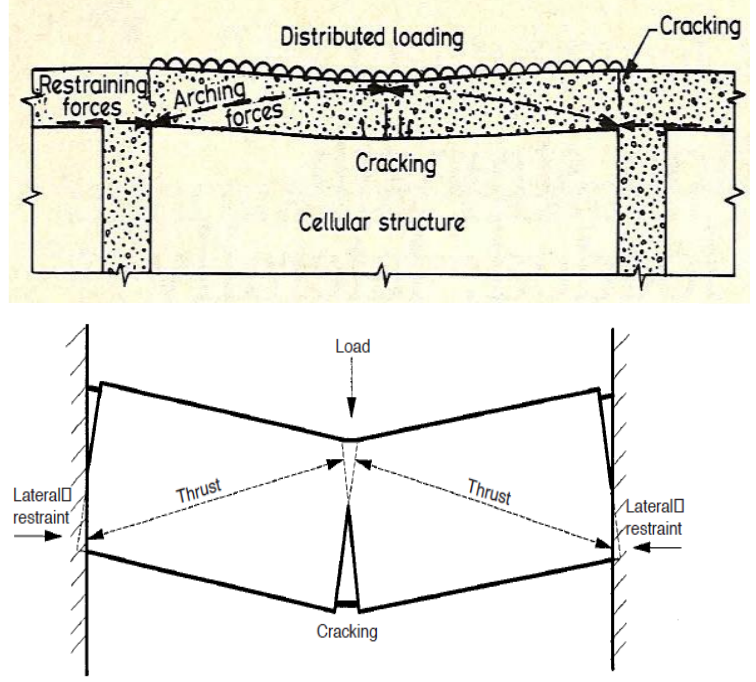

Fig. 1: Idealized illustration of the arching effect in a slab strip [1].

- The aspect ratios Ly/Lx of slab specimens were 1.0, 1.5, and 1.75 .

- The arrangement of longitudinal reinforcements varied as follows:

(i) Twenty specimens without reinforcement.

(ii) Two specimens with a single layer of reinforcement at the bottom.

(iii) Twenty-one specimens with two layers of reinforcement at top and bottom.

\section{Background}

Previous experimental and theoretical research into membrane action can be retraced to the early 20th century. In 1909, Turner[9] was one of the first researchers who acknowledged arching effects. He stated that "Such a slab will first act somewhat like a flat dome and slab combined, but as the deflection gradually increases it will gradually commence to act like a suspension system in which the concrete will mainly hold the rods together and distribute the load over them." Further, the favorable effect was recognized in 1921 by Westergaard [10] who had examined the structural behaviour of numerous full-scale tests on floor panels tested until collapse. Even though the influence of arch action was not basically discussed, the report can be considered to be the first to introduce and trigger the concept of membrane action. In 1945 the collapse of the Kimberly-Clark Warehouse building in Ontario, Canada takes place. Vecchio [11] considered the collapse of the building, which had an apparent factor of safety against collapse of 4.5 compared to design loads. Ockleston [12] tested a real structure in South Africa and recorded collapse loads that were four times the capacities predicted by yield-line theory

The most beneficial test results published on the topic of membrane action were related to the behaviour at small displacements of slabs with horizontal restraint along the edges. These types of concrete slabs are subjected to compressive membrane action, which allows a significant enhancement of the load-carrying capacity as shown in Fig. 2. The membrane action of concrete slabs occurring at large displacements, which is typically called tensile membrane action, includes slabs with horizontal restraint and vertical support around its edges as well as slabs that are free to move horizontally

[13]. 


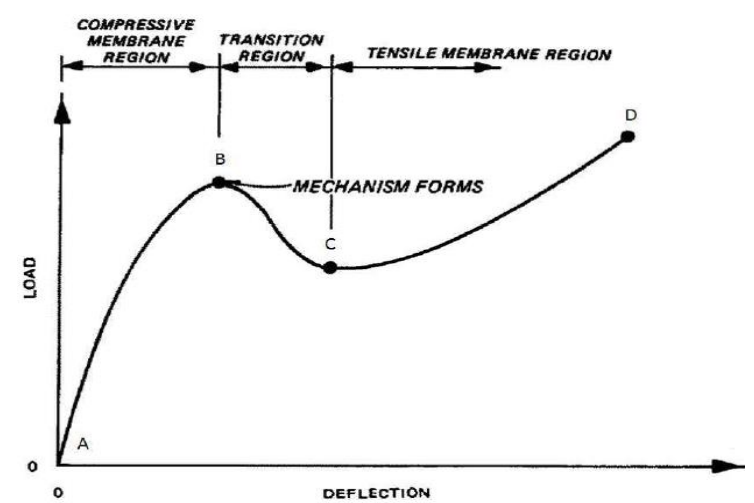

Fig. 2. Typical relationship between load and deflection for a restrained slab [14].

- Experimental studies on Compressive Membrane action

Powell [2] conducted the first laboratory tests on uniformly loaded laterally restrained reinforced concrete small-scale single panels with large span-to-depth ratios. Powell's dissertation established the starting point for a number of researchers including Park [3] who later developed the widely used compressive membrane theory referred to by many as the modified rigid-plastic theory. Park 3] and Wang [15] developed procedures depend on the assumption for the initial value of deflection in mid-span. Park [3] procedure assumed it to be $0.5 \mathrm{~d}$. This assumption failed to provide good predictions for tests by other researchers because the deflection at ultimate load was proven to be dependent on several parameters. Rankin and Long [1] developed a method of predicting the ultimate load capacity of restrained slab strips without the need for critical deflection predictions. Rankin [6] developed a method for the prediction of ultimate capacities of two-way concrete slabs without the need for critical deflection predictions. Then he modified his approach to predict the ultimate load capacity of restrained slab strips.

Taylor, Rankin and Cleland [16] carried out experimental tests on eight $1 / 3$ rd scale bridge deck edge panel with target compressive strengths of $100 \mathrm{~N} / \mathrm{mm}^{2}$. The authors concluded that the minimum horizontal deflections occurred with the widest beams. This highlights the effect of varying the degree of fixity of restraint. Muthu
[17] developed a method to predict the load-deflection behaviour of fully restrained reinforced concrete slab strips. The proposed analysis had been developed by modifying the rigid-plastic analysis of Eyre and Kemp [18]. Then Muthu [4] modified his approach to deal with partially restrained slab strips.

From previous studies, it is found that there are several factors affecting the CMA. These factors are the grade and percentage of reinforcement, the span-to-height ratio, the concrete compressive strength, and stiffness of the lateral restraint. The CMA decreased by increasing the grade or percentage of reinforcement and span-to-height ratio, whereas increased by increasing lateral support stiffness and concrete compressive strength. In addition, there is no simple reliable approach available to evaluate the CMA. Hence, a simple procedure to evaluate the CMA for fully laterally restrained RC two-way slabs, considering the above-mentioned factors, has been developed.

\section{METHODOLOGY}

The experimental data for five tests Powell [2], Park [3], Rankin [6], Park [19], and Keenan [20] were selected to be considered in this research. The five available tests give a reasonable representation of the variables encountered. These tests consisted of 43 specimens of two-way R.C slab which were fully restraint about all edges. The properties of these specimens were presented in Appendix (Table A.I and Table A.II). The major investigated factors are: (i) the percentage of reinforcement, and (ii) the span-to-height ratio. The stiffness of the lateral restraint and the concrete compressive strength were excluded because there is no valuable data available for two way RC slabs. The tests of Powell [2] and Park [19] were considered to investigate the effect of percentage of reinforcement. These tests consist of 13 specimens divided into two groups. These groups had span-to height ratio of 30 with bottom reinforcement of $50 \%$ of the top and same bottom and top reinforcement. The concrete compressive strength ranged from “27-34" $\mathrm{MPa}$ and 
"36-41" $\mathrm{MPa}$ for the two groups, respectively. The test ultimate capacities were compared with those capacities calculated using YLM. The tests of Park [3] and Park [19] were considered for investigating the effect of span-to-height ratio. These tests consist of 13 specimens, only 6 specimens without any reinforcement and concrete compressive strength ranged from "33-36" $\mathrm{MPa}$ were considered. The test ultimate capacities were directly compared with span-to-height ratio.

The 43 specimens' data was collected and sorted via excel program three times; (i)according to compressive strength, (ii) according to span-to-height ratio, (iii) according to the percentage of reinforcement, for simplicity of identifying relationships and making correlations. The correlation between the percentage of reinforcement and CMA was done for nine selected data from Powell [2] tests. The nine specimens have a span-to-height ratio of 30 , and a tight range of concrete compressive strength "36-41" MPa. The correlation was made to represent the difference between experimental capacity and Johansson yield line capacity based on reference point at $\mathrm{Q}=0.25 \%$. Then a correlation between the span-to-height ratio and CMA was carried out for selected data from references [2], [3], [6], [19] tests. All specimens had no reinforcement. The concrete compressive strength varied between 25 and $40 \mathrm{MPa}$. The correlation was made to represent the experimental capacity in terms of height-to-span ratio $(\mathrm{h} / \mathrm{Lr})$. A simple formula was achieved and has been validated by correlation with a wide range of test results from various sources.

\section{RESULTS AND DISCUSSION}

\subsection{Factors affecting the compressive membrane action}

\subsubsection{Percentage of reinforcement}

The relationship between CMA and the percentage of reinforcement is shown in Fig. 3 and Fig. 4. The distance between the two lines represents the CMA. This distance is decreased by increasing the percentage of reinforcement.

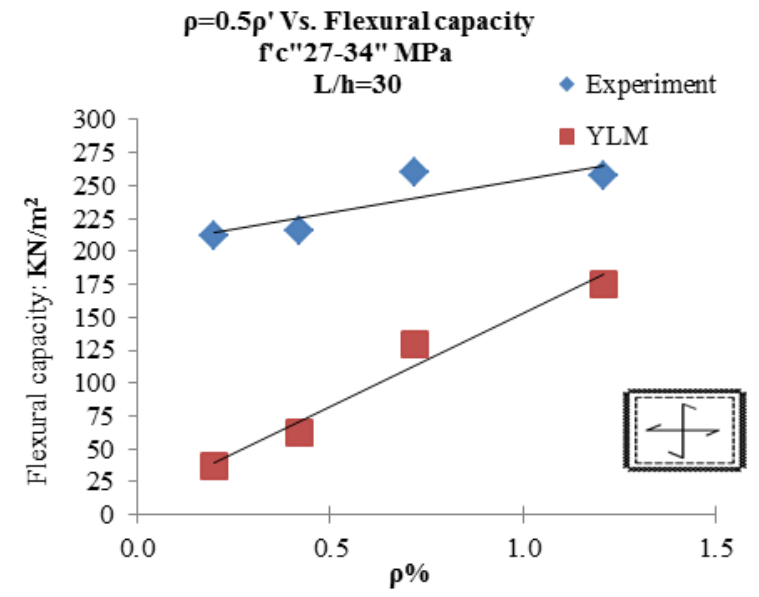

Fig. 3: The relation between the capacity and reinforcement percentage when $\varrho=0.5 \mathrm{Q}^{\prime}$

\subsubsection{Height-to-span ratio $h / L$ :}

In general, the load-carrying capacity of two-way R.C slab with larger thickness enhances as the effective height of section increases. However, it was shown that the additional load capacity due to CMA was also increased with larger thickness. The relationship between CMA and the height-to-span ratio is shown in Fig. 5. It explains the increase in specimens' capacity with increasing in height-to-span ratio.

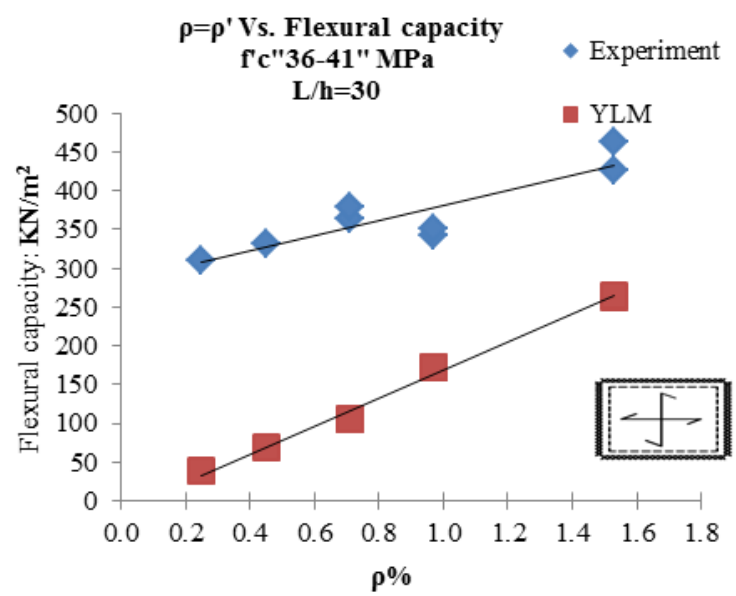

Fig. 4: The relation between the flexural capacity and reinforcement percentage when $\varrho^{\prime} \varrho^{\prime}$

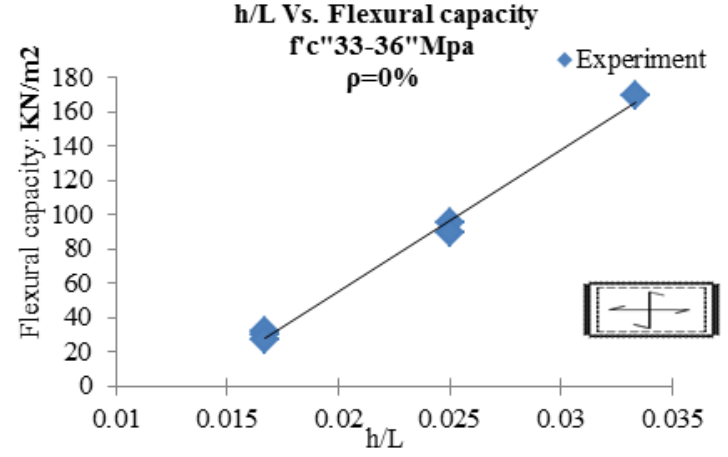

Fig. 5: The relation between the flexural capacity and span-to-height ratio 


\subsection{Development for numerical model}

As mentioned before only the percentage of reinforcement and span-to-height ratio were considered to represent the CMA in this model.

\subsubsection{Percentage of reinforcement:}

The correlation between the percentage of reinforcement and CMA was done as shown in Fig.6 for a selected data from reference [2] tests. Reversed relationship was noticed as expected, and the correlation was as follows:

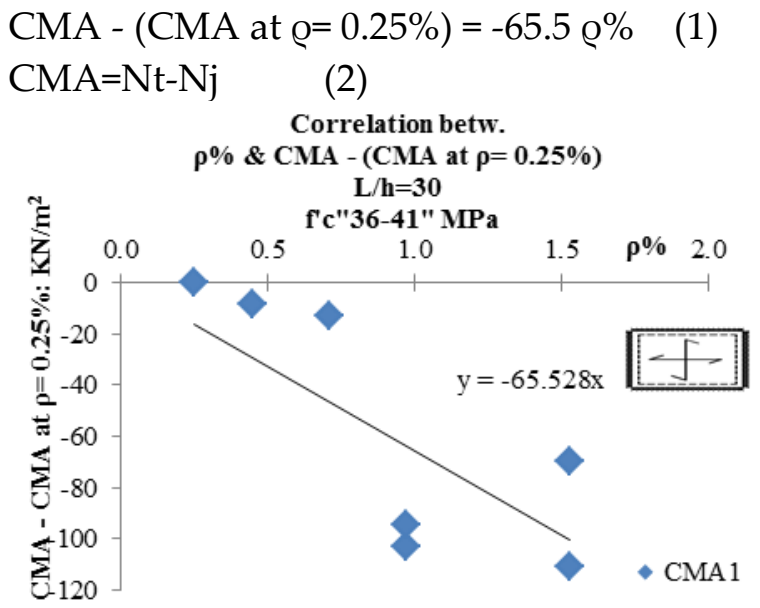

Fig. 6: The correlation between the percentage of reinforcement and CMA

\subsubsection{Span-to-height ratio:}

The correlation between the span-to-height ratio and CMA was shown in Fig.7. The relationship between the CMA and the height-to-span ratio $(\mathrm{h} / \mathrm{Lr}$ ) could be described as linear relationship since the CMA increases with h/Lr. Thus, the relationship can be written as follows:

$\mathrm{CMA}=6126.5(\mathrm{~h} / \mathrm{Lr})-184.2$

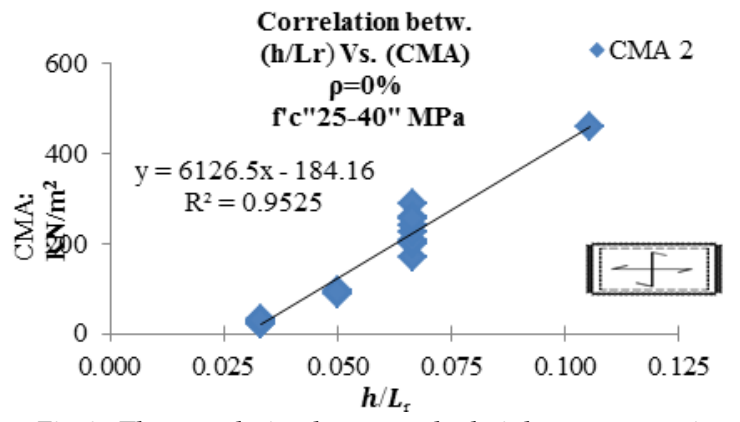

Fig. 7: The correlation between the height-to-span ratio and CMA

Fig. 7 shows the discrepancy between Powell [2] experimental results with $\mathrm{h} / \mathrm{Lr}$ of 0.067 , which have different capacity for the same of span-to-height ratio. Whereas Park [19] experimental results with $\mathrm{h} / \mathrm{Lr}$ of 0.033 has no discrepancy. This might be due to the different concrete compressive strengths used in the test. The ultimate capacity of the uniformly distributed load could be obtained by superposing the bending load and the additional load calculated from the following equation:

$$
\mathrm{CMA}=(6126.5(\mathrm{~h} / \mathrm{Lr})-184.2)-\left(65.5^{*} \mathrm{Q} \%\right) \mathrm{kN} / \mathrm{m}^{2} \quad(4)
$$

Correlation of the test results with above-proposed method resulted in an average ratio of tested-to-predicted ultimate capacity for the forty-three laterally restrained slab of 1.00 and a coefficient of variation of $25 \%$ as illustrated in Fig.8. It is of interest to note the good correlation of predicted values, despite the wide range of variables encountered in the analysis of the reported tests. Fig. 8. shows that the proposed approach overestimates some specimens' capacities; so a factor of safety should be used. It was found that 1.6 will be appropriate as shown in the figure.

\subsection{Comparison between the proposed and YL method:}

A summary of the comparison between the proposed and YLM is shown in Table I. The Johansson's yield line theory was found to highly underestimate the flexural capacity of the 43 specimens, with tested-to-predicted ranged from 1.5 to 8.12 , and mean capacity ratio of 3.29 . The mean ratio of the proposed method of tested-to-predicted ultimate capacity was 1.00 with a coefficient of variation of $25 \%$. This correlation can structural to be much better than that given by yield line and theory which resulted in an average ratio of tested-to-predicted ultimate capacity of 3.29, and a coefficient of variation of $54 \%$. The proposed method is considered to be satisfactory and gives reasonable results, especially in the view of the wide range of variables involved in these tests.

TABLE I: THE COMPARISON BETWEEN THE YL AND PROPOSED METHOD

\begin{tabular}{c|c|c}
\hline \hline & YLM & Proposed \\
\hline Mean & 3.29 & 1.00 \\
\hline Standard Deviation & 1.79 & 0.25 \\
\hline Cov. \% & 54 & 25 \\
\hline \hline
\end{tabular}




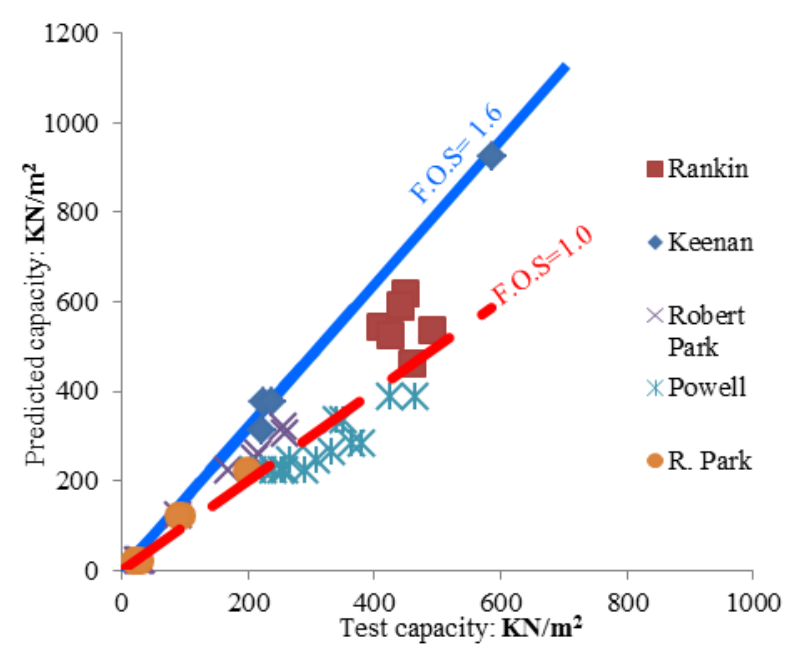

Fig. 8: Correlation of proposed method with 43 test results from various resources

\section{CONCLUSIONS}

The main goal of the paper is to identify the factors affecting the compressive membrane action in laterally restrained R.C two way slabs and develop a simple numerical model to evaluate it. A parametric study has been carried out to study the influence of certain physical parameters on the CMA in restrained flat plate slabs. The variables considered were the percentage of reinforcement and height-to-span ratio. This resulted in the following:

(i) The load enhancement due to compressive membrane action decreases by increasing the percentage of reinforcement.

(ii) The load enhancement due to compressive membrane action increases by increasing the height-to-span ratio. Thin slabs exhibit lower load enhancement compared to thick slabs.

(iii) The Johansson's yield line theory was found to highly underestimate the flexural capacity of the specimens, with a tested-to-predicted range from 1.5 to 8.12 , and an average ratio of 3.29 with a coefficient of variation of $54 \%$.

(iv) The proposed method resulted in an average ratio of tested-to-predicted ultimate capacity of 1.00 and a coefficient of variation of $25 \%$

(v) The proposed method of predicting capacity enhancement is relatively simple to use and yet it provides consistent good predictions of the ultimate capacities of uniformly loaded, two-way slab with rigid lateral restraints.

(vi) The proposed approach may overestimate some specimens' capacity; so a factor of safety should be used and it was found that 1.6 will be appropriate.

(vii)

\section{APPENDICES}

TABLE A.I: PROPERTIES OF REINFORCED SPECIMENS

\begin{tabular}{|c|c|c|c|c|c|c|}
\hline Author & $\begin{array}{c}\text { Nam } \\
\mathrm{e}\end{array}$ & $\begin{array}{c}\mathrm{f}^{\prime} \mathrm{c} \\
(\mathrm{MPa})\end{array}$ & $\begin{array}{c}\mathrm{h} \\
(\mathrm{m})\end{array}$ & $\begin{array}{c}\varrho \\
(\%)\end{array}$ & $\mathrm{Q}^{\prime}(\%)$ & $\begin{array}{c}\mathrm{Nt} \\
\mathrm{kN} / \mathrm{m}^{2}\end{array}$ \\
\hline \multirow{7}{*}{$\begin{array}{c}\text { Rankin[6] } \\
\text { Ly/Lx=1.0 } \\
\text { fy=510Mp } \\
\text { a } \\
\text { Ly=Lx=0.9 } \\
5 m\end{array}$} & S1R & 42.30 & 0.050 & 0 & 0 & 458.80 \\
\hline & S2R & 37.00 & 0.050 & 0.258 & 0.258 & 409.70 \\
\hline & S3R & 40.70 & 0.050 & 0.784 & 0.784 & 491.60 \\
\hline & S4R & 30.40 & 0.050 & 0.516 & 0.516 & 448.00 \\
\hline & S5R & 35.60 & 0.050 & 1.568 & 1.568 & 442.40 \\
\hline & S6R & 38.80 & 0.050 & 0.258 & 0.516 & 442.40 \\
\hline & S7R & 34.50 & 0.050 & 0.516 & 0 & 426.00 \\
\hline \multirow{4}{*}{$\begin{array}{c}\text { Keenan[20 } \\
] \\
\text { Ly/Lx=1.0 } \\
\text { fy=327Mp } \\
\text { a } \\
\text { Ly=Lx=1.8 } \\
288\end{array}$} & $3 S 1$ & 24.48 & $\begin{array}{c}0.076 \\
2 \\
\end{array}$ & 0.82 & 0.82 & 223.39 \\
\hline & $3 S 3$ & 28.48 & $\begin{array}{c}0.076 \\
2\end{array}$ & 0.82 & 0.82 & 238.56 \\
\hline & $3 S 4$ & 22.75 & $\begin{array}{c}0.076 \\
2 \\
\end{array}$ & 0.82 & 0.00 & 221.32 \\
\hline & $\begin{array}{c}4.75 S \\
1 \\
\end{array}$ & 21.79 & $\begin{array}{c}0.120 \\
65 \\
\end{array}$ & 0.89 & 0.89 & 586.05 \\
\hline \multirow{4}{*}{$\begin{array}{c}\text { Park[19] } \\
\text { Ly/Lx=1.5 } \\
\text { fy }=\{310-35 \\
0\} \mathrm{Mpa} \\
\mathrm{Ly}=1.524 \mathrm{~m} \\
\mathrm{Lx}=1.016 \mathrm{~m}\end{array}$} & A1 & 32.93 & $\begin{array}{c}0.050 \\
8 \\
\end{array}$ & 0.20 & 0.40 & 212.36 \\
\hline & A2 & 29.51 & $\begin{array}{c}0.050 \\
8 \\
\end{array}$ & 0.42 & 0.84 & 215.81 \\
\hline & A3 & 34.47 & $\begin{array}{c}0.050 \\
8 \\
\end{array}$ & 0.72 & 1.44 & 259.93 \\
\hline & A4 & 27.69 & $\begin{array}{c}0.050 \\
8 \\
\end{array}$ & 1.21 & 2.42 & 257.17 \\
\hline \multirow{9}{*}{$\begin{array}{c}\text { Powell[2] } \\
\text { Ly/Lx=1.7 } \\
5 \\
\text { fy= } 350 \mathrm{Mp} \\
\mathrm{a} \\
\mathrm{Ly}=0.9144 \\
\mathrm{~m} \\
\mathrm{Lx}=0.5225 \\
\mathrm{~m}\end{array}$} & S46 & 40.04 & $\begin{array}{c}0.032 \\
66\end{array}$ & 0.25 & 0.25 & 310.26 \\
\hline & S47 & 44.84 & $\begin{array}{c}0.032 \\
66 \\
\end{array}$ & 0.25 & 0.25 & 266.14 \\
\hline & S50 & 37.23 & $\begin{array}{c}0.032 \\
66 \\
\end{array}$ & 0.45 & 0.45 & 331.64 \\
\hline & S54 & 40.98 & $\begin{array}{c}0.032 \\
66 \\
\end{array}$ & 0.71 & 0.71 & 364.73 \\
\hline & S55 & 36.85 & $\begin{array}{c}0.032 \\
66 \\
\end{array}$ & 0.71 & 0.71 & 379.21 \\
\hline & S58 & 39.99 & $\begin{array}{c}0.032 \\
66 \\
\end{array}$ & 0.97 & 0.97 & 341.98 \\
\hline & S59 & 39.27 & $\begin{array}{c}0.032 \\
66 \\
\end{array}$ & 0.97 & 0.97 & 350.25 \\
\hline & S62 & 41.04 & $\begin{array}{c}0.032 \\
66 \\
\end{array}$ & 1.53 & 1.53 & 426.10 \\
\hline & S63 & 36.35 & $\begin{array}{c}0.032 \\
66 \\
\end{array}$ & 1.53 & 1.53 & 464.02 \\
\hline
\end{tabular}


TABLE A.II: PROPERTIES OF UN-REINFORCED SPECIMENS

\begin{tabular}{|c|c|c|c|c|}
\hline Author & Name & $\begin{array}{c}\mathrm{f}^{\prime} \mathrm{c} \\
(\mathrm{MPa}) \\
\end{array}$ & $\begin{array}{c}\mathrm{h} \\
(\mathrm{m}) \\
\end{array}$ & $\begin{array}{c}\mathrm{Nt} \\
\left(\mathrm{kN} / \mathrm{m}^{2}\right) \\
\end{array}$ \\
\hline \multirow{8}{*}{$\begin{array}{c}\text { Park[3] } \\
\text { Ly/Lx=1.5 } \\
\text { Ly=1.524m } \\
\text { Lx=1.016m }\end{array}$} & E1 & 26.42 & 0.02464 & 21.37 \\
\hline & E2 & 24.32 & 0.02413 & 23.58 \\
\hline & E3 & 26.31 & 0.02489 & 22.89 \\
\hline & $\mathrm{E} 4$ & 30.34 & 0.02413 & 20.13 \\
\hline & E5 & 35.58 & 0.02489 & 29.44 \\
\hline & E6 & 33.98 & 0.03759 & 95.15 \\
\hline & E7 & 31.11 & 0.03912 & 90.32 \\
\hline & E8 & 28.35 & 0.05258 & 198.57 \\
\hline \multirow{5}{*}{$\begin{array}{c}\text { Park[19] } \\
\text { Ly/Lx=1.5 } \\
\text { Ly=1.524m } \\
\text { Lx=1.016m }\end{array}$} & D1 & 34.64 & 0.05080 & 169.61 \\
\hline & D2 & 34.20 & 0.03810 & 88.94 \\
\hline & D3 & 35.47 & 0.02489 & 31.78 \\
\hline & D4 & 30.61 & 0.02565 & 28.54 \\
\hline & D5 & 35.52 & 0.02515 & 26.48 \\
\hline \multirow{6}{*}{$\begin{array}{c}\text { Powell[2] } \\
\mathrm{Ly} / \mathrm{Lx}=1.75 \\
\mathrm{Ly}=0.9144 \mathrm{~m} \\
\mathrm{Lx}=0.5225 \mathrm{~m}\end{array}$} & S48 & 41.04 & 0.03266 & 254.42 \\
\hline & S53 & 37.56 & 0.03266 & 289.58 \\
\hline & S56 & 38.22 & 0.03266 & 258.55 \\
\hline & S57 & 39.60 & 0.03266 & 208.22 \\
\hline & S60 & 39.66 & 0.03266 & 224.08 \\
\hline & S64 & 39.71 & 0.03266 & 241.32 \\
\hline
\end{tabular}

\section{REFERENCES}

[1] G. I. B. Rankin and A. E. Long, "Arching action strength enhancement in laterally-restrained slab strips," Proc. Inst. Civ. Eng. Struct. Build., vol. 122, no. 4, pp. 461-467, 1997.

[2] D. Powell, "The ultimate strength of concrete panels subjected to uniformly distributed loads," University of Cambridge, 1956.

[3] R. Park, "The ultimate strength and long-term behaviour of uniformly loaded, two-way concrete slabs with partial lateral restraint at all edges," Mag. Concr. Res., vol. 16, no. 48, pp. 139-152, 1964.

[4] K. U. Muthu, K. Amarnath, A. Ibrahim, and H. Mattarneh, "Load deflection behaviour of partially restrained slab strips," Eng. Struct., vol. 29 , no. 5, pp. 663-674, 2007.

[5] S. Nurmi, "Distributed sensing to assess the effect of axial restraint on reinforced concrete slabs," 2018.

[6] G. I. B. Rankin, R. A. Niblock, A. S. Skates, and A. E. Long, "Compressive membrane action strength enhancement in uniformly loaded, laterally restrained slabs," Struct. Eng. London, vol. 69, no. 16, pp. 287-295, 1991

[7] N. FarhangVesali, H. Valipour, B. Samali, and S. Foster, "Development of arching action in longitudinally-restrained reinforced concrete beams," Constr. Build. Mater., vol. 47, pp. 7-19, 2013.

[8] H. Valipour, N. Farhangvesali, and S. Foster, "A generic model for investigation of arching action in reinforced concrete members," Constr. Build. Mater., vol. 38, pp. 742-750, 2013.

[9] C. A. P. Turner, Concrete Steel Construction: Pt. 1-... Farnham Printing and Stationery Company, 1909.

[10] H. M. Westergaard and W. A. Slater, "Moments and stresses in slabs," in Journal Proceedings, 1921, vol. 17, no. 2, pp. 415-538.

[11] F. J. Vecchio and K. Tang, "Membrane action in reinforced concrete slabs," Can. J. Civ. Eng., vol. 17, no. 5, pp. 686-697, 1990.

[12] A. J. Ockleston, "Load tests on a three storey reinforced concrete building in Johannesburg," Struct. Eng., vol. 33, pp. 304-322, 1955.

[13] D. Gouverneur, R. Caspeele, and L. Taerwe, "Experimental investigation of the load-displacement behaviour under catenary action in a restrained reinforced concrete slab strip," Eng. Struct., vol. 49, pp.
1007-1016, 2013

[14] D. Gouverneur, "Experimental and Numerical analysis of tensile membrane action in reinforced concrete slabs in the framework of strucural robustness, PhD thesis," Ghent University, 2012.

[15] G. Wang, Q. X. Wang, and Z. J. Li, "Membrane action in lateral restraint reinforced concrete slabs," J. Cent. South Univ. Technol. (English Ed., vol. 18, no. 2, pp. 550-557, 2011.

[16] S. E. Taylor, G. I. B. Rankin, and D. J. Cleland, "Real strength of high-performance concrete bridge deck slabs," Proc. Inst. Civ. Eng. Bridg. Eng., vol. 156, no. 2, pp. 81-90, 2003.

[17] K. U. Muthu, K. Amarnath, A. Ibrahim, and H. Mattarneh, "Load--deflection behaviour of restrained RC slab strips," Struct. Concr., vol. 7, no. 1, pp. 17-26, 2006.

[18] J. R. Eyre and K. O. Kemp, "A graphical solution for predicting the increase in strength of concrete slabs due to membrane action," Mag. Concr. Res., vol. 35, no. 124, pp. 151-156, 1983.

[19] R. PARK, A. C. LIEBENBERG, R. H. WOOD, J. SCHLAICH, and W. SMYTH, "Discussion. Ultimate Strength of Rectangular Concrete Slabs Under Short-Term Uniform Loading With Edges Restrained Against Lateral Movement.," Proc. Inst. Civ. Eng., vol. 32, no. 1, pp 97-108, 1965.

[20] W. A. Keenan, "Strength and Behavior of Restrained Reinforced Concrete Slabs under Static and Dynamic Loadings (Technical Report R-621)," 1969.

[21] A. H. Mattock, L. B. Kriz, and E. Hognestad, "Rectangular concrete stress distribution in ultimate strength design," in Journal Proceedings, 1961, vol. 57, no. 2, pp. 875-928. 